\title{
Factors affecting in-hospital mortality of non-tuberculous mycobacterial pulmonary disease
}

Goh Tanaka1*, Taisuke Jo 1,2, Hiroyuki Tamiya', Yukiyo Sakamoto', Wakae Hasegawa', Hiroki Matsui', Kiyohide Fushimi ${ }^{4}$, Hideo Yasunaga ${ }^{3}$ and Takahide Nagase ${ }^{1}$

\begin{abstract}
Background: The incidence and prevalence of non-tuberculous mycobacterial pulmonary disease (NTM-PD) are reportedly increasing in many parts of the world. However, there are few published data on NTM-PD-related death. Using data from a national inpatient database in Japan, we aimed in this study to identify the characteristics of patients with NTM-PD and clinical deterioration and to identify risk factors for in-hospital mortality.

Methods: We examined data from the Diagnosis Procedure Combination (DPC) database in Japan from July 2010 to March 2014. We extracted data for HIV-negative NTM-PD patients who required unscheduled hospitalization. We evaluated these patients' characteristics and performed multivariable logistic regression analysis to identify risk factors for all-cause in-hospital mortality.

Results: A total of 16,192 patients (median age: 78 years; women: 61.2\%) were identified. The median body mass index (BMI) was $17.5 \mathrm{~kg} / \mathrm{m}^{2}$ (IQR 15.4-20.0). All cause In-hospital death occurred in 3166 patients (19.6\%). The median BMl of the patients who had died was $16.0 \mathrm{~kg} / \mathrm{m}^{2}$ (IQR 14.2-18.4). Multivariable analysis revealed that increased mortality was associated with male sex, lower BMI, lower activities of daily living scores on the Barthel index, hemoptysis, and comorbidities, including pulmonary infection other than NTM, interstitial lung disease, pneumothorax, and malignant disease.

Conclusions: We found associations between being underweight and having several comorbidities and increased in-hospital mortality in patients with NTM-PD. Preventing weight loss and management of comorbidities may have a crucial role in improving this disease's prognosis.
\end{abstract}

Keywords: Non-tuberculous mycobacterial disease, Hospital mortality, Body mass index

\section{Background}

Non-tuberculous mycobacterial pulmonary disease (NTM-PD) usually develops in middle-aged and older individuals, and is generally intractable and slowly progressive. The incidence and prevalence of NTM-PD are reportedly increasing in many parts of the world [1-7].

\footnotetext{
* Correspondence: gtanaka-tky@umin.ac.jp

'Department of Respiratory Medicine, The University of Tokyo, 7-3-1 Hongo, Bunkyo-ku, Tokyo 113-8655, Japan

Full list of author information is available at the end of the article
}

Increasing numbers of NTM-PD-related deaths among HIV-uninfected patients has also been reported in Japan [2] and the USA [8]. NTM-PD related deaths are expected to be a significant health problem in countries in which the population is aging.

Several population-based studies have identified the risk factors of male sex, older age, and some comorbidities for NTM-PD-related deaths [8-11]. Clinical conditions such as low body mass index (BMI) have also been shown to be associated with poor long-term prognosis

(c) The Author(s). 2021 Open Access This article is licensed under a Creative Commons Attribution 4.0 International License, which permits use, sharing, adaptation, distribution and reproduction in any medium or format, as long as you give appropriate credit to the original author(s) and the source, provide a link to the Creative Commons licence, and indicate if changes were made. The images or other third party material in this article are included in the article's Creative Commons licence, unless indicated otherwise in a credit line to the material. If material is not included in the article's Creative Commons licence and your intended use is not permitted by statutory regulation or exceeds the permitted use, you will need to obtain permission directly from the copyright holder. To view a copy of this licence, visit http://creativecommons.org/licenses/by/4.0/ The Creative Commons Public Domain Dedication waiver (http://creativecommons.org/publicdomain/zero/1.0/) applies to the data made available in this article, unless otherwise stated in a credit line to the data. 
of NTM-PD in some hospital-based studies [12, 13]; however, these studies had small patient cohorts. With regard to the significance of clinical deterioration of patients with NTM-PD, little information is available, particularly on in-hospital deaths. Evaluating risk factors for in-hospital mortality is crucial to improving the prognosis in patients with NTM-PD.

In this study, we used data from a nationwide database in Japan to investigate the characteristics and comorbidities of patients with NTM-PD who required unscheduled hospitalization and examined factors associated with in-hospital mortality in these patients.

\section{Methods}

\section{Data source}

We examined data from the Diagnosis Procedure Combination (DPC) database in Japan from July 2010 to March 2014. The database includes administrative claims data and discharge abstract data from more than 1200 hospitals, which covered $50 \%$ of the total bed capacity of acute care hospitals during the survey period. Primary diagnoses and comorbidities are recorded using International Statistical Classification of Diseases and Related Health Problems, 10th Revision (ICD-10) codes, accompanied by text data in Japanese. The database also contains the following information: age, sex, body height and weight, smoking status, grade of activity of daily living expressed as Barthel index score on admission, discharge status, therapeutic procedures, and medication use during hospitalization. This study was approved by the Institutional Review Board of The University of Tokyo and was performed in accordance with the
Declaration of Helsinki. The requirement for informed consent was waived because of the anonymous nature of the data.

\section{Patient selection and data}

We retrospectively extracted data for patients with ICD10 code: A310 (pulmonary mycobacterial infection) and A319 (Mycobacterial infection, unspecified). We did not include patients who were diagnosed with NTM extrapulmonary disease (ICD-10 code, A311 and A318) during the study period. We included only the last hospitalization of patients who required unscheduled hospitalization more than once during the study period. We excluded patients $<18$ years of age and those with HIV infection (ICD-10 code, B20-B24). We identified comorbidities using ICD-10 codes, as shown in Table 1. Because it is difficult to distinguish between primary bronchiectasis and bronchiectasis secondary to NTMPD [14], we did not include the comorbidity of bronchiectasis in our study.

To evaluate weight loss, we categorized BMI in accordance with the levels of severity of anorexia nervosa in the Diagnostic and Statistical Manual of Mental Disorders, Fifth Edition (DSM-5) [15].

We used either ICD-10 codes (R042, R048, and R049) or treatment with intravenous hemostatic agents (carbazochrome sodium sulfonate and/or tranexamic acid) as indicators of clinically significant hemoptysis or bloody sputum. We then excluded patients with diagnoses of hemorrhage from organs other than lungs (ICD-10 codes shown in Table 2) and those who had undergone endoscopic procedures for hemostasis of gastrointestinal

Table 1 ICD-10 codes used to identify comorbidities

\begin{tabular}{|c|c|}
\hline Comorbidity & ICD-10 codes \\
\hline Pulmonary infection & J100, J110, J12-J18, J20-22, J85, J86, J690 \\
\hline Pulmonary aspergillosis & B44 \\
\hline COPD & $J 43, J 440, J 441, J 449$ \\
\hline Bronchial asthma & $J 45, J 46$ \\
\hline Interstitial lung disease & J841, J848, J849 \\
\hline Pneumothorax & J93 \\
\hline Congestive heart failure & I110, I500, I501, 1509 \\
\hline Ischemic heart disease & $120-125$ \\
\hline Cerebrovascular disease & $160-169$ \\
\hline Renal disease & N00-08, N10-N19 \\
\hline Autoimmune disease & M05, M06, M08, M30-M35 \\
\hline Diabetes mellitus & E10-E14 \\
\hline Bone fracture & S02, S12, S22, S32, S42, S52, S62, S72, S82, S92, T02, T10, T12 \\
\hline Lung cancer & C33, C34 \\
\hline Hematological malignancy & $\mathrm{C} 81-\mathrm{C} 85, \mathrm{C} 88, \mathrm{C} 90-\mathrm{C} 96$ \\
\hline Other malignant disease & C00-C97 \\
\hline
\end{tabular}


Table 2 ICD-10 codes used to identify hemorrhage from organs other than lung

\begin{tabular}{|c|c|}
\hline & ICD-10 codes \\
\hline Hemorrhage from urinary system & N288, N300, N304, N309, N328, N368, N421, N421, N488, N501, E274 \\
\hline Hemorrhage associated with gynecological disease & $\begin{array}{l}\text { N645, N830, N831, N838, N908, N921-N924, N930, N938, N939, N950, } \\
\text { N988, O209, O441, O469, O679, O695, O720-O722, O730, O731 }\end{array}$ \\
\hline Hemorrhage associated with otolaryngological disease & E078, H603, H669, H738, H922, R040, R041 \\
\hline Intracerebral hemorrhage & $160-162$ \\
\hline Spinal cord hemorrhage & G951, G968 \\
\hline Ocular hemorrhage & $\mathrm{H} 113, \mathrm{H} 168, \mathrm{H} 208, \mathrm{H} 210, \mathrm{H} 313, \mathrm{H} 350, \mathrm{H} 356, \mathrm{H} 357, \mathrm{H} 405, \mathrm{H} 431, \mathrm{H} 448, \mathrm{H} 470$ \\
\hline Traumatic hemorrhage & S013, S051, S063, S066, S068, S098, S368, S378, T144, T794 \\
\hline Postoperative hemorrhage & T810, T811 \\
\hline
\end{tabular}

tract bleeding. We considered that arterial embolization performed in patients with hemoptysis was bronchial artery embolization.

In addition, we extracted data concerning oral and intravenous treatment with various drugs, including corticosteroids and anti-mycobacterial agents. We evaluated prescription of the following antibiotics: rifamycins, including rifampicin and rifabutin; ethambutol; isoniazid; macrolides, including clarithromycin and azithromycin; aminoglycosides, including streptomycin, kanamycin, and amikacin; fluoroquinolones, including levofloxacin, moxifloxacin and sitafloxacin; and imipenem/cilastatin. We then assessed the combination of rifamycin, ethambutol, and clarithromycin, which is the recommended first line therapy for Mycobacterium avium complex pulmonary disease (MAC-PD) in Japan [16]. We also evaluated prescription of erythromycin, which has an antiinflammatory effect in patients with chronic airway diseases.

\section{Statistical analysis}

We used $x^{2}$ tests to compare baseline characteristics, treatments, and procedures during hospitalization between patients who died during hospitalization and those who survived. We performed multivariable logistic regression to identify risk factors for all-cause in-hospital mortality. We used multiple imputation by the chained equations technique to deal with missing data on BMI, smoking history, and Barthel index scores. We included all the variables analyzed in this study in the imputation model and created $20 \mathrm{im}$ puted datasets. We fitted multivariable logistic regression analyses for in-hospital mortality with generalized estimating equations to account for within-hospital clustering [17]. We obtained one set of statistical results on each imputed dataset and integrated them using Rubin's combination rules [18]. We set statistical significance at less than 0.05 for all analyses. We performed statistical analyses using Stata/ MP version 14 (StataCorp, College Station, TX, USA).

\section{Results}

\section{Patient characteristics}

We identified 16,280 patients with NTM-PD who required unscheduled hospitalization during the study period. We then excluded 24 patients aged $<18$ years and 64 patients with HIV infection from the study, leaving 16,192 patients who were eligible for further analysis.

These patients characteristics are shown in Table 3. The median age was 78 years (interquartile range [IQR] 71-84) and $61.2 \%$ were women. The overall median BMI was $17.5 \mathrm{~kg} / \mathrm{m}^{2}$ (IQR 15.4-20.0), being $18.1 \mathrm{~kg} / \mathrm{m}^{2}$ (IQR 15.9-20.6) for men and $17.2 \mathrm{~kg} / \mathrm{m}^{2}$ (IQR $15.2-$ 19.5) for women. The most common comorbidity was pulmonary infection other than NTM (50.8\%). As for primary diagnosis during hospitalization, pulmonary diseases accounted for $68.3 \%$ (pulmonary infection $28.8 \%$, NTM-PD 23.1\%, and other pulmonary disease 16.4\%). Malignant diseases and other non-pulmonary diseases accounted for 4.1 and $27.6 \%$, respectively.

\section{Treatments during hospitalization}

Treatments during hospitalization are shown in Table 4; $44.6 \%$ of the 16,192 patients had not received any antibiotics with antimicrobial activity against NTM during the hospitalization, $3.2 \%$ had received monotherapy with erythromycin, and $15.2 \%$ had been treated with combination therapy including rifamycin, ethambutol and clarithromycin. Corticosteroids were prescribed for $20.9 \%$ of all patients.

\section{All-cause in-hospital mortality}

Overall, 3166 patients (19.6\%) died during their unscheduled hospitalizations (Table 3). The median age of these patients was 80 years (IQR 74-85). The median BMI of all patients who died in hospital was $16.0 \mathrm{~kg} / \mathrm{m}^{2}$ (IQR 14.2-18.4), comprising $16.6 \mathrm{~kg} / \mathrm{m}^{2}$ (IQR $14.8-19.1$ ) for men and $15.4 \mathrm{~kg} / \mathrm{m}^{2}$ (IQR 13.7-17.6) for women. The median length of hospital stay was 18 days (IQR 10-34) in all patients and 21 days (IQR 8-44) in patients 
Table 3 Baseline characteristics of patients with NTM pulmonary disease who required unscheduled hospitalization

\begin{tabular}{|c|c|c|c|c|c|}
\hline & \multirow{2}{*}{\multicolumn{2}{|c|}{$\frac{\text { Total }(\%)}{n=16,192}$}} & \multicolumn{2}{|c|}{ Death (\%) } & \multirow[t]{2}{*}{$P$-value } \\
\hline & & & \multicolumn{2}{|c|}{$n=3166$} & \\
\hline Sex & & & & & $<0.001$ \\
\hline Male & 6283 & $(38.8)$ & 1543 & (48.7) & \\
\hline Female & 9909 & $(61.2)$ & 1623 & (51.3) & \\
\hline Age, years & & & & & $<0.001$ \\
\hline$<70$ & 3400 & $(21.0)$ & 455 & $(14.4)$ & \\
\hline $70-79$ & 5374 & $(33.2)$ & 1035 & (32.7) & \\
\hline$\geq 80$ & 7418 & $(45.8)$ & 1676 & (52.9) & \\
\hline BMI, kg/m² & & & & & $<0.001$ \\
\hline$<15.0$ & 2858 & $(17.7)$ & 910 & (28.7) & \\
\hline $15.0-15.9$ & 1627 & $(10.0)$ & 371 & (11.7) & \\
\hline $16.0-16.9$ & 1714 & (10.6) & 297 & (9.4) & \\
\hline $17.0-18.4$ & 2533 & (15.6) & 365 & (11.5) & \\
\hline $18.5-24.9$ & 5036 & $(31.1)$ & 568 & (17.9) & \\
\hline$\geq 25.0$ & 476 & $(2.9)$ & 44 & (1.4) & \\
\hline Missing data & 1948 & (12.0) & 611 & (19.3) & \\
\hline Activities of daily living, Barthel index & & & & & $<0.001$ \\
\hline 100 & 5137 & $(31.7)$ & 354 & $(11.2)$ & \\
\hline $75-95$ & 1553 & (9.6) & 159 & $(5.0)$ & \\
\hline $50-70$ & 1921 & $(11.9)$ & 336 & (10.6) & \\
\hline $25-45$ & 1225 & $(7.6)$ & 296 & $(9.3)$ & \\
\hline $0-20$ & 3818 & $(23.6)$ & 1426 & $(45.0)$ & \\
\hline Missing data & 2538 & $(15.7)$ & 595 & $(18.8)$ & \\
\hline Smoking history & & & & & $<0.001$ \\
\hline No & 11,373 & $(70.2)$ & 2083 & (65.8) & \\
\hline Yes & 3167 & $(19.6)$ & 668 & $(21.1)$ & \\
\hline Missing data & 1652 & $(10.2)$ & 415 & $(13.1)$ & \\
\hline \multicolumn{6}{|l|}{ Symptom } \\
\hline Hemoptysis & 2996 & $(18.5)$ & 528 & $(16.7)$ & 0.003 \\
\hline \multicolumn{6}{|l|}{ Comorbidity } \\
\hline \multicolumn{6}{|l|}{ Pulmonary disease } \\
\hline Pulmonary infection & 8225 & $(50.8)$ & 2024 & (63.9) & $<0.001$ \\
\hline Pulmonary aspergillosis & 874 & $(5.4)$ & 261 & $(8.2)$ & $<0.001$ \\
\hline COPD & 1527 & $(9.4)$ & 362 & $(11.4)$ & $<0.001$ \\
\hline Bronchial asthma & 1158 & $(7.2)$ & 181 & $(5.7)$ & $<0.001$ \\
\hline Interstitial lung disease & 1171 & $(7.2)$ & 384 & $(12.1)$ & $<0.001$ \\
\hline Pneumothorax & 730 & $(4.5)$ & 183 & $(5.8)$ & $<0.001$ \\
\hline \multicolumn{6}{|l|}{ Non-pulmonary disease } \\
\hline Congestive heart failure & 2279 & $(14.1)$ & 650 & (20.5) & $<0.001$ \\
\hline Ischemic heart disease & 1123 & $(6.9)$ & 184 & $(5.8)$ & 0.006 \\
\hline Cerebrovascular disease & 1248 & $(7.7)$ & 243 & $(7.7)$ & 0.94 \\
\hline Renal disease & 853 & $(5.3)$ & 218 & (6.9) & $<0.001$ \\
\hline Autoimmune disease & 1225 & (7.6) & 198 & (6.3) & 0.002 \\
\hline Diabetes mellitus & 2289 & $(14.1)$ & 460 & $(14.5)$ & 0.48 \\
\hline
\end{tabular}


Table 3 Baseline characteristics of patients with NTM pulmonary disease who required unscheduled hospitalization (Continued)

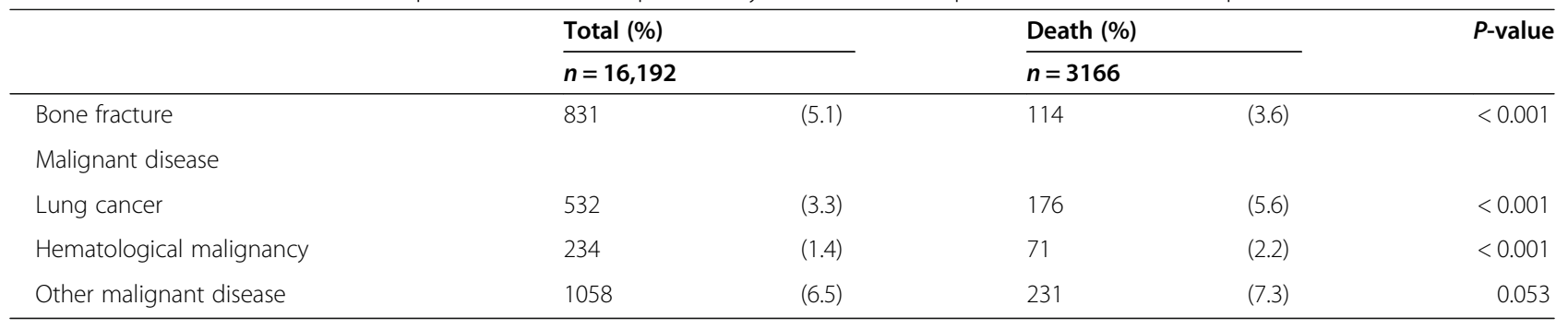

who died during hospitalization. Two-thirds of the patients who required mechanical ventilation died during the hospitalization (Table 4).

Table 5 shows the results of the multivariable logistic regression analysis for all-cause in-hospital mortality. Higher in-hospital mortality was associated with male sex, lower BMI, lower Barthel index score, hemoptysis, and comorbidities, including pulmonary infection other than NTM, pulmonary aspergillosis, interstitial lung disease, pneumothorax, congestive heart failure, renal disease, and malignant disease.

\section{Discussion}

In this study, we analyzed in-hospital mortality using data of more than 16,000 patients with NTM-PD drawn from a nationwide database in Japan. Pulmonary diseases accounted for $68.3 \%$ of primary diagnoses during these patients' hospitalizations. The results of multivariable logistic regression analysis showed that male sex, lower BMI, lower Barthel index score, and hemoptysis were associated with higher in-hospital mortality. Several comorbidities were also associated with higher mortality.

Table 4 Treatment of study patients during hospitalization

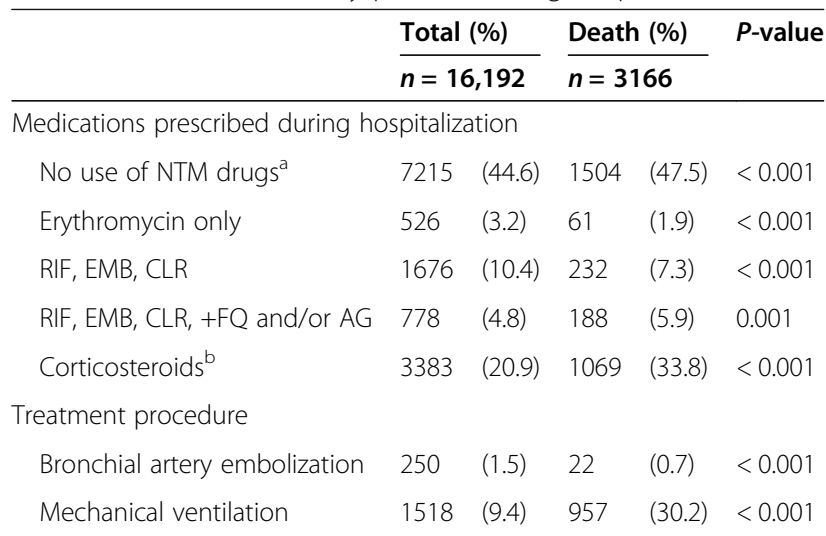

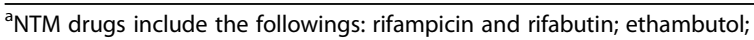
isoniazid; macrolides, including clarithromycin and azithromycin; aminoglycosides, including streptomycin, kanamycin and amikacin fluoroquinolones, including levofloxacin, moxifloxacin and sitafloxacin; and imipenem/cilastatin

${ }^{b}$ Corticosteroids include those administered both orally and intravenously Abbreviations: $A G$ aminoglycoside, $C L R$ clarithromycin, EMB ethambutol, $F Q$ fluoroquinolone, NTM non-tuberculous mycobacterial pulmonary disease, RIF rifampicin
Several previous population-based studies have evaluated risk factors for NTM-related deaths. These studies identified older age $[8,9,11,19]$ and male sex [9-11, 19] as potential risk factors for NTM-related deaths. Several comorbid diseases were also shown to be possible risk factors, including chronic obstructive pulmonary disease (COPD) [8, 11], lung cancer [10, 11, 19], bronchial asthma [10], pneumonia [10], and interstitial lung disease [11]. Bloody sputum was also associated with mortality in one single center study [20].

In the present study, we found that most of the participants $(50.8 \%)$ had comorbid pulmonary infections in addition to NTM. Furthermore, pulmonary infection was significantly associated with in-hospital mortality, whereas, COPD and bronchial asthma were not. It remains unknown why COPD and bronchial asthma were not associated with higher in-hospital mortality. One possibility is that some of the patients hospitalized for exacerbations of COPD or bronchial asthma had better treatment responses.

Almost $90 \%$ of NTM-PD in Japan is reportedly MACPD [3]. In the present study, $15.2 \%$ of the patients received combination therapy including rifampicin, ethambutol, and clarithromycin, which is a standard regimen for MAC-PD, whereas $44.6 \%$ did not receive any antibiotics that target NTM. It seems likely that a relatively large proportion of patients in our study required unscheduled hospitalization for management of comorbid diseases or conditions.

In a previous study of 178 patients with NTM-PD from Oregon, USA, regular use of immunosuppressive medication was a risk factor for death [19]. In our study, about one third of patients who received corticosteroids after admission died during hospitalization. It is possible that most of the patients who were treated with corticosteroids had severe comorbidities on admission. Further studies are needed to elucidate the association between regular use of corticosteroids and prognosis of NTMPD.

This study included BMI data in the multivariable analysis for mortality; to the best of our knowledge, no published studies have examined BMI prior to death in patients with NTM-PD. However, several studies have reported an association between weight loss and 
Table 5 Results of multivariable logistic regression analysis with multiple imputation for all-cause in-hospital mortality in patients with NTM pulmonary disease who required unscheduled hospitalization

\begin{tabular}{|c|c|c|c|}
\hline & OR & $95 \% \mathrm{Cl}$ & $P$-value \\
\hline \multicolumn{4}{|l|}{ Sex } \\
\hline Male & 1.89 & $(1.70-2.10)$ & $<0.001$ \\
\hline \multicolumn{4}{|l|}{ Age, years } \\
\hline$<70$ & reference & & \\
\hline $70-79$ & 1.12 & $(0.98-1.29)$ & 0.11 \\
\hline$\geq 80$ & 1.04 & $(0.90-1.20)$ & 0.56 \\
\hline \multicolumn{4}{|l|}{$\mathrm{BMI}, \mathrm{kg} / \mathrm{m}^{2}$} \\
\hline$<15.0$ & 3.15 & $(2.74-3.62)$ & $<0.001$ \\
\hline $15.0-15.9$ & 2.15 & $(1.81-2.54)$ & $<0.001$ \\
\hline $16.0-16.9$ & 1.57 & $(1.31-1.87)$ & $<0.001$ \\
\hline $17.0-18.4$ & 1.31 & $(1.13-1.52)$ & $<0.001$ \\
\hline $18.5-24.9$ & reference & & \\
\hline$\geq 25.0$ & 0.83 & $(0.58-1.18)$ & 0.30 \\
\hline
\end{tabular}

Activities of daily living, Barthel index

\begin{tabular}{|c|c|c|c|}
\hline 100 & reference & & \\
\hline 75-95 & 1.45 & $(1.19-1.78)$ & $<0.001$ \\
\hline $50-70$ & 2.58 & $(2.18-3.06)$ & $<0.001$ \\
\hline $25-45$ & 3.74 & $(3.07-4.55)$ & $<0.001$ \\
\hline $0-20$ & 7.72 & $(6.68-8.92)$ & $<0.001$ \\
\hline \multicolumn{4}{|l|}{ Smoking history } \\
\hline Yes & 0.89 & $(0.78-1.01)$ & 0.077 \\
\hline \multicolumn{4}{|l|}{ Symptom } \\
\hline Hemoptysis & 1.21 & $(1.07-1.37)$ & 0.002 \\
\hline \multicolumn{4}{|l|}{ Comorbidity } \\
\hline \multicolumn{4}{|l|}{ Pulmonary disease } \\
\hline Pulmonary infection & 1.70 & $(1.54-1.87)$ & $<0.001$ \\
\hline Pulmonary aspergillosis & 1.65 & $(1.39-1.96)$ & $<0.001$ \\
\hline COPD & 0.96 & $(0.83-1.12)$ & 0.63 \\
\hline Bronchial asthma & 0.81 & $(0.68-0.98)$ & 0.027 \\
\hline Interstitial lung disease & 2.77 & $(2.37-3.24)$ & $<0.001$ \\
\hline Pneumothorax & 1.40 & $(1.14-1.73)$ & 0.001 \\
\hline \multicolumn{4}{|l|}{ Non-pulmonary disease } \\
\hline Congestive heart failure & 1.62 & $(1.43-1.83)$ & $<0.001$ \\
\hline Ischemic heart disease & 0.79 & $(0.66-0.95)$ & 0.011 \\
\hline Cerebrovascular disease & 0.75 & $(0.63-0.88)$ & 0.001 \\
\hline Renal disease & 1.46 & $(1.21-1.76)$ & $<0.001$ \\
\hline Autoimmune disease & 0.85 & $(0.72-1.01)$ & 0.072 \\
\hline Diabetes mellitus & 1.03 & $(0.90-1.18)$ & 0.65 \\
\hline Bone fracture & 0.49 & $(0.39-0.61)$ & $<0.001$ \\
\hline Malignant disease & 2.07 & $(1.79-2.39)$ & $<0.001$ \\
\hline
\end{tabular}

development of NTM-PD [12, 13, 21-23]. In this study, patients with NTM-PD who required unscheduled hospitalization had remarkably low BMIs, the median being $17.5 \mathrm{~kg} / \mathrm{m}^{2}$. Furthermore, lower BMI was strongly associated with higher in-hospital mortality. Our findings are in line with those of other hospital-based studies assessing long-term prognosis of MAC-PD patients in Japan, which have repeatedly shown that a BMI of less than $18.5 \mathrm{~kg} / \mathrm{m}^{2}$ is associated with higher mortality [12, 13]. It is possible that most of the patients who died during their hospitalizations had cachexia, which is recognized as a complex metabolic syndrome [24].

Development of more effective anti-mycobacterial drugs may be crucial to preventing progression of NTM-PD. However, such drugs may not completely prevent progression of NTM-PD because some patients are likely to have polyclonal and mixed NTM infections acquired from the environment, as well as reinfection with NTM after treatment $[25,26]$. Taken together, exploring host factors (such as the mechanisms by which severe weight loss affects susceptibility to, and progression of, NTM-PD) may be important in improving the prognosis of this disease. In fact, two previous studies have reported a possible role for inappropriately secreted adipokines in the pathogenesis of NTM-PD [27, 28]; however, their results were inconsistent and thus require further investigation.

Several limitations must be acknowledged. First, mild cases of NTM-PD without respiratory complications may have not been recorded by the attending physician; this would have resulted in low sensitivity for the diagnosis of mild cases of NTM-PD. NTM-PD is more likely to be diagnosed when it is has resulted in moderate to severe respiratory symptoms. Second, we may have underestimated the proportion of patients who were receiving combination therapy for MAC-PD because antimycobacterial drugs prescribed in the outpatient settings are usually withdrawn on admission in more severe cases. This would have prevented us from accurately evaluating the association between antibacterial therapies for NTM-PD and in-hospital mortality.

\section{Conclusions}

In the present study of data drawn from a nationwide inpatient database in Japan, we identified multiple factors associated with in-hospital mortality of NTM-PD. In particular, we found associations between pulmonary infection other than NTM and lower BMI and higher inhospital mortality. Controlling for severe weight loss and comorbidities may play a key role in improving the prognosis of this disease.

\section{Abbreviations}

BMI: Body mass index; COPD: Chronic obstructive pulmonary disease; DPC: Diagnosis Procedure Combination; DSM-5: Diagnostic and Statistical 
Manual of Mental Disorders, Fifth Edition; ICD-10: International Statistical Classification of Diseases and Related Health Problems, 10th Revision; IQR: Interquartile range; MAC-PD: Mycobacterium avium complex pulmonary disease; NTM-PD: Non-tuberculous mycobacterial pulmonary disease

\section{Acknowledgements}

Not applicable.

\section{Authors' contributions}

G.T. and T.J. take responsibility for the integrity of the data and have final responsibility for the decision to submit the manuscript for publication. G.T. and T.J. had full access to the data. G.T., T.J., and T.N. designed and supervised the project. H.M., K.F. and H.Y. contributed to acquisition of data. G.T., T.J., H.T., Y.S., W.H., and H.Y. contributed to statistical analysis and interpretation of the results. G.T., T.J. and H.Y. drafted and finalized the manuscript. All authors have critically read, and approved, the final version of the manuscript.

\section{Funding}

This work was supported by grants from the Ministry of Health, Labour and Welfare, Japan (19AA2007 and 20AA2005) and the Ministry of Education, Culture, Sports, Science and Technology, Japan (20H03907).

\section{Availability of data and materials}

Data cannot be made publicly available for ethical reasons as the data are patient data. The data are available to interested researchers upon reasonable request to the corresponding author, pending ethical approval.

\section{Declarations}

\section{Ethics approval and consent to participate}

Conduct of the study was approved by the Institutional Review Board of The University of Tokyo, which waived the requirement for informed consent owing to the anonymity of the data. This study was performed in accordance with the Declaration of Helsinki.

\section{Consent for publication}

Not applicable.

\section{Competing interests}

The authors declare that they have no competing interests.

\section{Author details}

'Department of Respiratory Medicine, The University of Tokyo, 7-3-1 Hongo, Bunkyo-ku, Tokyo 113-8655, Japan. ²Department of Health Services Research, Graduate School of Medicine, The University of Tokyo, Tokyo, Japan. ${ }^{3}$ Department of Clinical Epidemiology and Health Economics, School of Public Health, Graduate School of Medicine, The University of Tokyo, Tokyo, Japan. ${ }^{4}$ Department of Health Policy and Informatics, Tokyo Medical and Dental University Graduate School of Medicine, Tokyo, Japan.

Received: 13 January 2021 Accepted: 14 July 2021

Published online: 20 July 2021

\section{References}

1. Marras TK, Mendelson D, Marchand-Austin A, May K, Jamieson FB. Pulmonary nontuberculous mycobacterial disease, Ontario, Canada, 19982010. Emerg Infect Dis. 2013;19(11):1889-91. https://doi.org/10.3201/eid1 911.130737.

2. Morimoto K, Iwai K, Uchimura K, Okumura M, Yoshiyama T, Yoshimori K, et al. A steady increase in nontuberculous mycobacteriosis mortality and estimated prevalence in Japan. Ann Am Thorac Soc. 2014;11(1):1-8. https:// doi.org/10.1513/AnnalsATS.201303-0670C.

3. Namkoong H, Kurashima A, Morimoto K, Hoshino Y, Hasegawa N, Ato M, et al. Epidemiology of pulmonary nontuberculous mycobacterial disease, Japan. Emerg Infect Dis. 2016;22(6):1116-7. https://doi.org/10.3201/eid2206.1 51086.

4. Ringshausen FC, Wagner D, de Roux A, Diel R, Hohmann D, Hickstein L, et al. Prevalence of nontuberculous mycobacterial pulmonary disease, Germany, 2009-2014. Emerg Infect Dis. 2016;22(6):1102-5. https://doi.org/1 0.3201/eid2206.151642.
5. Izumi K, Morimoto K, Hasegawa N, Uchimura K, Kawatsu L, Ato M, et al. Epidemiology of adults and children treated for nontuberculous mycobacterial pulmonary disease in Japan. Ann Am Thorac Soc. 2019;16(3): 341-7. https://doi.org/10.1513/AnnalsATS.201806-3660C.

6. Lee H, Myung W, Koh WJ, Moon SM, Jhun BW. Epidemiology of nontuberculous mycobacterial infection, South Korea, 2007-2016. Emerg Infect Dis. 2019;25(3):569-72. https://doi.org/10.3201/eid2503.1 81597.

7. Winthrop KL, Marras TK, Adjemian J, Zhang H, Wang P, Zhang Q. Incidence and prevalence of nontuberculous mycobacterial lung disease in a large $U$. S. managed care health plan, 2008-2015. Ann Am Thorac Soc. 2020;17(2): 178-85. https://doi.org/10.1513/AnnalsATS.201804-2360C.

8. Vinnard C, Longworth S, Mezochow A, Patrawalla A, Kreiswirth BN, Hamilton K. Deaths related to nontuberculous mycobacterial infections in the United States, 1999-2014. Ann Am Thorac Soc. 2016;13(11):1951-5. https://doi. org/10.1513/AnnalsATS.201606-474BC.

9. Andrejak C, Thomsen VO, Johansen IS, Riis A, Benfield TL, Duhaut $P$, et al. Nontuberculous pulmonary mycobacteriosis in Denmark: incidence and prognostic factors. Am J Respir Crit Care Med. 2010;181(5):514-21. https:// doi.org/10.1164/rccm.200905-07780C

10. Adjemian J, Olivier KN, Seitz AE, Holland SM, Prevots DR. Prevalence of nontuberculous mycobacterial lung disease in U.S. Medicare beneficiaries. Am J Respir Crit Care Med. 2012;185(8):881-6. https://doi.org/10.1164/rccm.2 01111-20160C.

11. Marras TK, Campitelli MA, Lu H, Chung H, Brode SK, Marchand-Austin A, et al. Pulmonary nontuberculous mycobacteria-associated deaths, Ontario, Canada, 2001-2013. Emerg Infect Dis. 2017;23(3):468-76. https://doi.org/1 $0.3201 /$ eid2303.161927.

12. Hayashi M, Takayanagi N, Kanauchi T, Miyahara Y, Yanagisawa T, Sugita Y. Prognostic factors of 634 HIV-negative patients with Mycobacterium avium complex lung disease. Am J Respir Crit Care Med. 2012;185(5):575-83. https://doi.org/10.1164/rccm.201107-12030C.

13. Kumagai S, Ito A, Hashimoto T, Marumo S, Tokumasu H, Kotani A, et al. Development and validation of a prognostic scoring model for Mycobacterium avium complex lung disease: an observational cohort study. BMC Infect Dis. 2017;17(1):436. https://doi.org/10.1186/s12879-017-2544-0.

14. Griffith DE, Aksamit T, Brown-Elliott BA, Catanzaro A, Daley C, Gordin F, et al. An official ATS/IDSA statement: diagnosis, treatment, and prevention of nontuberculous mycobacterial diseases. Am J Respir Crit Care Med. 2007; 175(4):367-416. https://doi.org/10.1164/rccm.200604-571ST.

15. American Psychiatric Association. Diagnostic and statistical manual of mental disorders, fifth edition (DSM-5 $\left.{ }^{\oplus}\right)$. Washington, DC: American Psychiatric Association Publishing; 2013. https://doi.org/10.1176/appi.books. 9780890425596

16. Japanese Society of Tuberculosis, Japanese Society of Respiratory Diseases. Opinions on chemotherapy of non-tuberculous acid-fast bacterial infection of the lung. Kekkaku. 2012;87:83-6 (in Japanese).

17. Aloisio KM, Micali N, Swanson SA, Field A, Horton NJ. Analysis of partially observed clustered data using generalized estimating equations and multiple imputation. Stata J. 2014;14(4):863-83. https://doi.org/10.1177/153 $6867 \times 1401400410$

18. Rubin DB. Multiple imputation for nonresponse in surveys: John Wiley \& Sons; 1987. https://doi.org/10.1002/9780470316696.

19. Novosad SA, Henkle E, Schafer S, Hedberg K, Ku J, Siegel SAR, et al. Mortality after respiratory isolation of nontuberculous mycobacteria. A comparison of patients who did and did not meet disease criteria. Ann Am Thorac Soc. 2017;14(7):1112-9. https://doi.org/10.1513/AnnalsATS.201610-8000C.

20. Gochi M, Takayanagi N, Kanauchi T, Ishiguro T, Yanagisawa T, Sugita Y. Retrospective study of the predictors of mortality and radiographic deterioration in 782 patients with nodular/bronchiectatic Mycobacterium avium complex lung disease. BMJ Open. 2015;5(8):e008058. https://doi.org/1 0.1136/bmjopen-2015-008058.

21. Song JH, Kim BS, Kwak N, Han KD, Yim JJ. Impact of body mass index on development of nontuberculous mycobacterial pulmonary disease. Eur Respir J. 2021;57(2):2000454. PMID: 32817261.

22. Kim RD, Greenberg DE, Ehrmantraut ME, Guide SV, Ding L, Shea Y, et al. Pulmonary nontuberculous mycobacterial disease: prospective study of a distinct preexisting syndrome. Am J Respir Crit Care Med. 2008;178(10): 1066-74. https://doi.org/10.1164/rccm.200805-6860C.

23. Koh WJ, Jeong BH, Jeon K, Lee NY, Lee KS, Woo SY, et al. Clinical significance of the differentiation between Mycobacterium avium and 
Mycobacterium intracellulare in M avium complex lung disease. Chest. 2012; 142(6):1482-8. https://doi.org/10.1378/chest.12-0494.

24. Evans WJ, Morley JE, Argiles J, Bales C, Baracos V, Guttridge D, et al. Cachexia: a new definition. Clin Nutr. 2008;27(6):793-9. https://doi.org/10.1 016/j.cInu.2008.06.013.

25. Fujita K, Ito Y, Hirai T, Kubo T, Maekawa K, Togashi K, et al. Association between polyclonal and mixed mycobacterial Mycobacterium avium complex infection and environmental exposure. Ann Am Thorac Soc. 2014; 11(1):45-53. https://doi.org/10.1513/AnnalsATS.201309-2970C.

26. Wallace RJ Jr, Brown-Elliott BA, McNulty S, Philley JV, Killingley J, Wilson RW, et al. Macrolide/azalide therapy for nodular/bronchiectatic mycobacterium avium complex lung disease. Chest. 2014;146(2):276-82. https://doi.org/1 0.1378/chest.13-2538.

27. Tasaka S, Hasegawa N, Nishimura T, Yamasawa W, Kamata H, Shinoda H, et al. Elevated serum adiponectin level in patients with Mycobacterium avium-intracellulare complex pulmonary disease. Respiration. 2010;79(5): 383-7. https://doi.org/10.1159/000231975.

28. Kartalija M, Ovrutsky AR, Bryan CL, Pott GB, Fantuzzi G, Thomas J, et al. Patients with nontuberculous mycobacterial lung disease exhibit unique body and immune phenotypes. Am J Respir Crit Care Med. 2013;187(2):197205. https://doi.org/10.1164/rccm.201206-10350C.

\section{Publisher's Note}

Springer Nature remains neutral with regard to jurisdictional claims in published maps and institutional affiliations.

Ready to submit your research? Choose BMC and benefit from:

- fast, convenient online submission

- thorough peer review by experienced researchers in your field

- rapid publication on acceptance

- support for research data, including large and complex data types

- gold Open Access which fosters wider collaboration and increased citations

- maximum visibility for your research: over $100 \mathrm{M}$ website views per year

At $\mathrm{BMC}$, research is always in progress.

Learn more biomedcentral.com/submissions 